\title{
openheart Operative survival in patients with acute aortic disease in the era of newer oral anticoagulants
}

\author{
Johannes Lagethon Bjørnstad (D) , ${ }^{1,2}$ Adil Mahboob Khan, ${ }^{1}$ \\ Henriette Røed-Undlien, ${ }^{2}$ Bjørn Bendz (D) , ${ }^{2,3}$ Ståle Nygård, ${ }^{4}$ Tom Nilsen Hoel, ${ }^{1}$ \\ Per Snorre Lingaas ${ }^{1}$
}

\begin{abstract}
- Additional material is published online only. To view please visit the journal online (http://dx.doi.org/10.1136/ openhrt-2020-001278).
\end{abstract}

To cite: Bjørnstad JL, Khan AM, Røed-Undlien $\mathrm{H}$, et al. Operative survival in patients with acute aortic disease in the era of newer oral anticoagulants. Open Heart 2020;7:e001278. doi:10.1136/

openhrt-2020-001278

Received 27 February 2020 Revised 16 April 2020 Accepted 18 May 2020

\section{Check for updates}

(c) Author(s) (or their employer(s)) 2020. Re-use permitted under CC BY-NC. No commercial re-use. See rights and permissions. Published by BMJ.

${ }^{1}$ Department of Cardiothoracic Surgery, Oslo University Hospital, Oslo, Norway ${ }^{2}$ Institute of Clinical Medicine, University of Oslo, Oslo, Norway ${ }^{3}$ Department of Cardiology, 0slo University Hospital, Oslo, Norway ${ }^{4}$ Department of Biostatistics, Oslo Centre for Biostatistics and Epidemiology, University of Oslo, Oslo, Norway

Correspondence to Dr Johannes Lagethon Bjørnstad; johannes.bjornstad@ ous-hf.no

\section{ABSTRACT}

Aims The aim of this study was the analysis of the risk associated with direct oral anticoagulants (DOACs) in patients undergoing non-elective operations on the proximal aorta due to aortic disease.

Methods and results Data from the department's register of cardiac surgery was analysed retrospectively with emphasis on operative mortality. 135 non-elective operations for proximal aortic disease (0ctober 2016 to 2018) were identified, of which 19 died during the first 90 days. DOAC use was the top-ranked risk factor in the univariate analysis with a HR of 9.6 (3.1 to 29), $p=0.00007$. Using a Cox proportional hazards model including the most relevant risk factors, the risk associated with DOAC use remained significant with a HR of 6.1 (1.4 to 26.3), $p=0.015$. We did not find increased risk associated with warfarin use.

Conclusion In patients undergoing non-elective operations on the proximal aorta due to aortic disease, the use of DOAC is associated with increased operative mortality.

\section{INTRODUCTION}

Bleeding is a well-known complication in cardiac surgery. ${ }^{1}$ As most patients undergoing cardiac surgery have an indication for platelet inhibitors or anticoagulant medication, cardiac surgeons develop clinical experience with these drugs. Where previously aspirin and warfarin were the repertoire, several platelet inhibitors have now demonstrated their usefulness, and in the recent years, direct oral anticoagulants (DOACs), also referred to as non-vitamin $\mathrm{K}$ oral anticoagulants, have challenged warfarin as the oral anticoagulant of choice. While the effect of warfarin is influenced by diet and must be monitored by blood tests (International Normalised Ratio (INR)), the DOACs are more convenient to use, as blood tests are not needed to monitor the therapeutic effect and there are no clear diet interactions. Large clinical trials have demonstrated their effectiveness in atrial fibrillation. ${ }^{2-5}$ In Norway, DOACs have gained popularity and, of anticoagulant users in 2018, 27\% used warfarin and $73 \%$

\section{Key questions}

What is already known about this subject?

- In Norway, newer direct oral anticoagulants (DOACs) have now nearly replaced warfarin in patients with need for anticoagulation. DOACs are easier to use and are supposed to be safer than warfarin. Lack of access to antidote is a concern in case of bleeding and/or acute surgery.

What does this study add?

- Our study describes increased operative mortality in DOAC users undergoing non-elective operations on the proximal aorta due to aortic disease. In DOAC users, mortality was due to bleeding-related complications. To our knowledge, this is the first study indicating negative effects of DOACs on operative survival. Even though acute aortic surgery is a frequent cardiac surgical emergency, it still remains a special situation in which coagulopathy is common, both due to the disease and the surgery performed.

How might this impact on clinical practice?

- As we report increased operative mortality in DOAC users undergoing non-elective operations on the proximal aorta due to aortic disease, risk factors for aortic dissection should be taken into consideration when prescribing anticoagulant medication.

used DOAC. ${ }^{6}$ During the DOAC era, cardiac surgeons have recognised that these drugs are potent anticoagulants, and a need for up to 10 days withdrawal prior to cardiac surgery has been suggested. ${ }^{7}$ To evaluate our clinical experience of bleeding-related complications in DOAC users, we explored and analysed data from the register of cardiac surgery at the Department of Cardiothoracic Surgery.

\section{METHODS}

\section{Study design and population}

Following a major revision of our department's register of cardiac surgery, the use of DOAC was registered from October 2016 onward. This register is approved by 
the institutional board of ethics. Recommendation in processing personal data or health information was given by the hospital's data protection officer according to institution protocol. We analysed 2658 open cardiac operations in adults from October 2016 through 2018. Survival status was updated according to information obtained by the Norwegian National Registry. Three patients were non-residents, and for these, discharge is used as the last observation. Operative survival was defined as surviving beyond 90 days after the operation and operative survival was explored by anticoagulant/platelet inhibitor and urgency. Thus, all-cause mortality is used in the analyses. Among 527 non-elective cardiac operations in adults, surgery on the proximal aorta, thoracic transplants, valve procedures and isolated coronary artery bypass surgery were the most frequent procedures. Thoracic transplant recipients were excluded as DOACs routinely are withdrawn prior to the patients being listed for transplant. For patients undergoing urgent coronary artery bypass surgery or valve surgery, the operation is postponed for a few days to allow for withdrawal of anticoagulants or dual platelet inhibitors when considered safe. Aortic disease was the indication for most non-elective operations on the proximal aorta, followed by endocarditis. A few patients suffered from other conditions. We therefore decided to analyse the effect of DOACs in non-elective operations involving the proximal aorta (root, ascending and/or arch) due to aortic disease (International Classification of Diseases-10 I71.x).

\section{Statistical methods}

Continuous variables are presented as median (IQR). To compare continuous variables Kruskal-Wallis rank sum and Wilcoxon rank-sum tests were used. Categorical variables were compared using Pearson's $\chi^{2}$ contingency table test. To perform Cox proportional hazard models, categorical variables containing more than two groups were recoded with dummy variables. We performed a careful selection of variables to identify the most relevant factors for the final multivariate analysis, as there only were 19 operative deaths in this small series. Of 59 risk factors, 20 factors had more than $30 \%$ missing values due to the urgent nature of these operations and these variables were excluded from analyses because of missingness. Of the remaining variables, 33 were more than $90 \%$ completely registered. After recoding risk factors and operation types to Boolean variables and removing one variable (postinfarctseptal rupture) that was negative for all, there were 46 different risk variables. For the survival analysis, multiple imputations were used to address missing data in the remaining variables. We also analysed the data set setting missing values to 'No', however giving the same main findings. We identified 23 variables with $p$ value $\leq 0.3$ in the univariate analysis. As EuroSCORE, serum creatinine and estimated glomerular filtration rate had a significant number of missing values due to conversion in the register from EuroSCORE I to II during the study period, these were among the risk factors not included in the analyses. The EuroSCORE II risk factors renal impairment, pulmonary hypertension and weight of the intervention were recoded to joint variables based on EuroSCORE I using the corresponding EuroSCORE II value (eg, 'severe' or dialysis). With LASSO (least absolute shrinkage and selection operator) regression, we identified four important risk factors (DOAC use, extracardiac

Table 1 Operative data (single platelet inhibitor or less, warfarin, DAPT or DOAC)

\begin{tabular}{|c|c|c|c|c|c|c|}
\hline & & $\begin{array}{l}\text { Single platelet } \\
\text { inhibitor or less }\end{array}$ & Warfarin & DAPT & DOAC & \\
\hline Number of operations & $\mathrm{n}$ & 108 & 8 & 13 & 6 & \\
\hline Aortic root replacement & $n$ & 7 & 0 & 3 & 0 & \\
\hline Aortic arch repair & $\mathrm{n}$ & 3 & 0 & 0 & 0 & \\
\hline Extracorporeal circulation & $\%$ & 100 & 100 & 100 & 100 & \\
\hline Duration of extracorporeal circulation & $\min$ & $107(68)$ & $104(16)$ & $173(67)$ & $97(129)$ & * DAPT vs warfarin/less \\
\hline Duration of aortic cross clamp & $\min$ & $47(35)$ & $44(30)$ & $82(52)$ & $61(63)$ & ${ }^{\star}$ DAPT vs less \\
\hline Deep hypothermic circulatory arrest & $\%$ & 100 & 88 & 92 & 100 & * \\
\hline Duration of circulatory arrest & $\min$ & $15(6)$ & $20(15)$ & $16.5(3.75)$ & $15(8.75)$ & \\
\hline Cell saver used & $\%$ & 49 & 25 & 38 & 75 & \\
\hline Intraoperative haemofiltration & $\%$ & 44 & 25 & 46 & 83 & \\
\hline
\end{tabular}

${ }^{*} \mathrm{p}<0.05$

DAPT, dual anti-platelet inhibitors; DOAC, direct oral anticoagulants . 
Table 2 Risk factors by anticoagulant/platelet inhibitor use (single platelet inhibitor or less, warfarin, DAPT or DOAC)

\begin{tabular}{|c|c|c|c|c|c|c|}
\hline & & Single platelet inhibitor or less & Warfarin & DAPT & DOAC & \\
\hline Number of operations & $\mathrm{n}$ & 108 & 8 & 13 & 6 & \\
\hline Age & $\mathrm{y}$ & $67(14.2)$ & $69.5(14.8)$ & $51(22)$ & $75.5(6.5)$ & ${ }^{*}$ DOAC vs DAPT \\
\hline Hypercholesterolaemia & $\%$ & 19 & 33 & 40 & 17 & \\
\hline Diabetes on insulin & $\%$ & 1 & 14 & 0 & 0 & \\
\hline Chronic pulmonary disease & $\%$ & 15 & 40 & 23 & 0 & \\
\hline Extracardiac arteriopathy & $\%$ & 19 & 67 & 38 & 33 & * \\
\hline Poor mobility & $\%$ & 19 & 38 & 23 & 0 & * \\
\hline Previous cardiac surgery & $\%$ & 1 & 38 & 0 & 0 & * \\
\hline Prior PCl & $\%$ & 5 & 29 & 33 & 0 & * \\
\hline Unstable angina & $\%$ & 1 & 0 & 42 & 0 & * \\
\hline Arrhythmia & $\%$ & 11 & 57 & 8 & 67 & * \\
\hline History of severe ventricular arrhythmia & $\%$ & 3 & 0 & 8 & 0 & \\
\hline Permanent pacemaker/CRT & $\%$ & 1 & 12 & 0 & 0 & \\
\hline Left ventricular dysfunction & $\%$ & 14 & 50 & 27 & 0 & \\
\hline Pulmonary hypertension & $\%$ & 3 & 0 & 0 & 0 & \\
\hline Critical preoperative state & $\%$ & 64 & 75 & 85 & 83 & \\
\hline Thoracic aortic aneurysm & $\%$ & 70 & 62 & 77 & 50 & \\
\hline
\end{tabular}

${ }^{*} \mathrm{p}<0.05$

CRT, Cardiac resynchronisation therapy ; DAPT, dual anti-platelet inhibitors; DOAC, direct oral anticoagulants ; PCI, Percutaneous coronary intervention; $y$, years.

Table 3 Medication at admission (single platelet inhibitor or less, warfarin, DAPT or DOAC)

\begin{tabular}{|c|c|c|c|c|c|c|}
\hline & & Single platelet inhibitor or less & Warfarin & DAPT & DOAC & \\
\hline Number of operations & $\mathrm{n}$ & 108 & 8 & 13 & 6 & \\
\hline DOAC & $\%$ & 0 & 0 & 0 & 100 & * \\
\hline Statins & $\%$ & 18 & 25 & 25 & 17 & \\
\hline Nitrates & $\%$ & 6 & 12 & 8 & 17 & \\
\hline Warfarin & $\%$ & 0 & 100 & 0 & 0 & * \\
\hline Heparin & $\%$ & 4 & 25 & 62 & 0 & * \\
\hline Corticosteroids & $\%$ & 5 & 14 & 15 & 0 & \\
\hline Calcium antagonists & $\%$ & 10 & 38 & 17 & 50 & * \\
\hline Beta blockers & $\%$ & 18 & 50 & 8 & 67 & * \\
\hline Angiotensin receptor blockers & $\%$ & 16 & 25 & 27 & 50 & \\
\hline Aspirin & $\%$ & 25 & 50 & 100 & 17 & * \\
\hline Other immunosuppresants & $\%$ & 2 & 0 & 0 & 0 & \\
\hline Other platelet inhibitor than aspirin & $\%$ & 2 & 25 & 100 & 17 & * \\
\hline Angiotensin-converting enzyme inhibitors & $\%$ & 10 & 14 & 18 & 0 & \\
\hline
\end{tabular}

${ }^{*} \mathrm{p}<0.05$

DAPT, dual anti-platelet inhibitors; DOAC, direct oral anticoagulants. 
Open Heart

Table 4 Postoperative data by anticoagulant/platelet inhibitor. Patients not surviving the operation were excluded from the upper part of this table. (Single platelet inhibitor or less, warfarin, DAPT or DOAC.)

\begin{tabular}{|c|c|c|c|c|c|c|}
\hline & & Single platelet inhibitor or less & Warfarin & DAPT & DOAC & \\
\hline Number of operations & $\mathrm{n}$ & 107 & 8 & 13 & 5 & \\
\hline PO length of stay & days & $4(2)$ & $4.5(3)$ & $7(7)$ & $3(1)$ & \\
\hline PO ICU stay & days & $2(3)$ & $2.5(1.75)$ & $2(4.5)$ & $1(3)$ & \\
\hline P0 ventilator $>24$ hour & $\%$ & 23 & 25 & 23 & 50 & \\
\hline PO reintubated & $\%$ & 6 & 0 & 0 & 20 & \\
\hline P0 renal replacement therapy & $\%$ & 4 & 0 & 15 & 0 & \\
\hline PO circulatory support & $\%$ & 0 & 0 & 8 & 0 & \\
\hline PO bleeding & $\mathrm{ml}$ & $660(990)$ & $615(550)$ & $820(870)$ & $820(3246)$ & \\
\hline Any transfusion & $\%$ & 96 & 100 & 92 & 100 & \\
\hline erythrocytes & units & $3(4.75)$ & $2(2)$ & $5(4)$ & $19(21)$ & \\
\hline plasma & units & $5(5.75)$ & $2.5(3.25)$ & $5(4)$ & $12(20)$ & ${ }^{*}$ DOAC vs warfarin \\
\hline thrombocytes & units & $1(1)$ & $1(1.25)$ & $1(3)$ & $4(6)$ & \\
\hline PO autotransfusion & $\%$ & 32 & 38 & 15 & 75 & \\
\hline P0 autotransfusion & $\mathrm{ml}$ & $0(450)$ & $0(518)$ & $0(0)$ & $591(521)$ & \\
\hline PO nitrous oxide & $\%$ & 0 & 0 & 0 & 0 & \\
\hline PO pulmonary artery catheter & $\%$ & 0 & 0 & 0 & 20 & * \\
\hline PO superficial infection & $\%$ & 1 & 0 & 0 & 0 & \\
\hline P0 pneumonia & $\%$ & 9 & 12 & 15 & 20 & \\
\hline P0 other infection & $\%$ & 4 & 12 & 0 & 0 & \\
\hline P0 mediastinitis & $\%$ & 1 & 0 & 0 & 0 & \\
\hline PO inotropic support & $\%$ & 10 & 38 & 42 & 20 & * \\
\hline P0 sternal dehiscence & $\%$ & 0 & 0 & 0 & 0 & \\
\hline P0 revision for bleeding & $\%$ & 9 & 12 & 15 & 60 & * \\
\hline PO CPR & $\%$ & 4 & 12 & 0 & 0 & \\
\hline P0 septicaemia & $\%$ & 1 & 0 & 8 & 0 & \\
\hline P0 arrhythmia & $\%$ & 24 & 50 & 33 & 40 & \\
\hline P0 pacemaker $>24$ hour & $\%$ & 4 & 0 & 8 & 0 & \\
\hline P0 new chest tube & $\%$ & 2 & 12 & 0 & 25 & * \\
\hline PO myocardial infarction & $\%$ & 1 & 0 & 0 & 0 & \\
\hline P0 stroke & $\%$ & 9 & 25 & 15 & 0 & \\
\hline P0 paraparesis & $\%$ & 4 & 0 & 8 & 0 & \\
\hline PO other reoperation & $\%$ & 5 & 0 & 38 & 20 & * \\
\hline PO failure in other organs & $\%$ & 8 & 0 & 15 & 0 & \\
\hline P0 delayed cardiac tamponade & $\%$ & 3 & 12 & 8 & 40 & * \\
\hline $\mathrm{PO}$ return to ICU & $\%$ & 7 & 0 & 0 & 0 & \\
\hline P0 pressure ulcer & $\%$ & 0 & 0 & 0 & 0 & \\
\hline P0 mobilised $<24$ hour & $\%$ & 70 & 50 & 54 & 40 & \\
\hline $\mathrm{n}$ & & 108 & 8 & 13 & 6 & \\
\hline PO in-department mortality & $\%$ & 2 & 25 & 8 & 33 & * \\
\hline 30 days mortality & $\%$ & 8 & 25 & 8 & 67 & * \\
\hline
\end{tabular}

${ }^{*} \mathrm{p}<0.05$

CPR, Cardiopulmonary resuscitation; DAPT, dual anti-platelet inhibitors; DOAC, direct oral anticoagulants ; ICU, intensive care unit; PO, postoperative. 


\begin{tabular}{|c|c|c|}
\hline & HR (95\% Cl for HR) & $P$ value \\
\hline DOAC use & 9.6 (3.1 to 29$)$ & 0.000069 \\
\hline Extracardiac arteriopathy & 6.9 (2.6 to 18$)$ & 0.000097 \\
\hline Abdominal aneurysm & 5 (1.9 to 13$)$ & 0.0011 \\
\hline $\begin{array}{l}\text { Angiotensin II receptor blocker } \\
\text { use }\end{array}$ & $4.3(1.7$ to 11$)$ & 0.0015 \\
\hline Arrhythmia & 4.1 (1.7 to 10$)$ & 0.0023 \\
\hline Diabetes on insulin & $3.6(0.84$ to 16$)$ & 0.084 \\
\hline Previous PCl & 3.2 (1.2 to 9$)$ & 0.025 \\
\hline Heparin use & $3.2(1.2$ to 8.9$)$ & 0.026 \\
\hline Calicium antagonist use & 2.9 (1.1 to 7.6$)$ & 0.031 \\
\hline Other platelet inhibiting drugs & $3.1(1.2$ to 8.1$)$ & 0.023 \\
\hline $\begin{array}{l}\text { History of severe ventricular } \\
\text { arrhythmia }\end{array}$ & 3.1 (1.2 to 8.1$)$ & 0.023 \\
\hline ACE inhibitor use & 2.5 (0.83 to 7.6$)$ & 0.1 \\
\hline Recent myocardial infarction & 2.5 (0.82 to 7.4$)$ & 0.11 \\
\hline Previous myocardial infarction & $2.2(0.79$ to 6.1$)$ & 0.13 \\
\hline Diabetes without insulin & 2.1 (0.61 to 7.2$)$ & 0.24 \\
\hline Chronic pulmonary disease & $2.1(0.78$ to 5.4$)$ & 0.15 \\
\hline Thoracic aneurysm & $1.9(0.65$ to 5.9$)$ & 0.24 \\
\hline Critical preoperative state & 2 (0.65 to 5.9$)$ & 0.23 \\
\hline Nitrate use & $1.9(0.56$ to 6.6$)$ & 0.3 \\
\hline Renal failure & $1.9(0.64$ to 5.8$)$ & 0.24 \\
\hline Hypertension & 1.8 (0.67 to 5.1$)$ & 0.24 \\
\hline Beta blocker use & $1.7(0.64$ to 4.5$)$ & 0.29 \\
\hline Age & 1 (0.99 to 1.1$)$ & 0.15 \\
\hline
\end{tabular}

DOAC, direct oral anticoagulants ; PCI, Percutaneous coronary intervention.

arteriopathy, angiotensin II receptor blocker use and abdominal aortic aneurysm). We then included these risk factors and age, as DOAC users seemed a bit older, as well as warfarin use (for comparison), in a Cox proportional hazards model. The proportional hazards assumption was tested for each covariate. We also performed a Cox proportional hazards model with stepwise algorithm, including the risk factors identified in the univariate analysis as covariates. This resulted in higher HR and wider CI, but the same main finding. In this analysis, DOAC use, diabetes requiring insulin, history of severe ventricular arrhythmia, use of other platelet inhibitors than aspirin and angiotensin II receptor blocker use were considered to be the most important factors. RStudio was used for the statistical analyses (RStudio Team (2016). RStudio: Integrated Development for R. RStudio, Inc, Boston, Massachusetts; URL: http://www.rstudio.com/).

\section{RESULTS}

A total of 135 non-elective operations on the proximal aorta for aortic disease were identified. The indication for surgery was aortic dissection in 126 and aneurysm in
9. In three operations, the aortic arch was repaired and in 10 the root was replaced. In the remaining 122 the ascending aorta was replaced with a supracoronary graft or hemi-arch procedure and in one of these, the aortic valve was also replaced (table 1). Patients using DOAC were older and patients using DOAC or warfarin more frequently had a history of cardiac arrhythmias (table 2).

In the DOAC group, 30-day mortality rate was $67 \%$ versus $9 \%$ in patients not using DOAC. All deaths among the DOAC-treated patients were bleeding related, while this was not the case in any of the other groups. Medication at admission is shown in table 3. Postoperative data are affected by early and intraoperative mortality, especially in the DOAC-treated patients where one out of five died only a few hours postoperatively (table 4 ). The two patients that died intraoperatively (one DOAC user and one patient using neither platelet inhibitors nor anticoagulants) are not included in the table demonstrating the postoperative observations. History of myocardial infarction and previous PCI were more common among warfarin users and in patients using dual anti-platelet inhibitors (DAPT), while DAPT users had a higher incidence of myocardial infarction during the last 3 months.

Five patients used both platelet inhibitors and anticoagulation. Among the DAPT users, there was one patient using DOAC and two patients using warfarin additionally. Two patients used aspirin in addition to warfarin. Of these five, only two of the patients survived; one was using warfarin and aspirin, and the other was using warfarin and DAPT. These patients are allocated to the respective anticoagulant group in the tables.

Thirty-eight per cent of warfarin users had previously been operated via sternotomy, vs $0.8 \%$ of patients not using warfarin (table 2). A significant number of DOAC users were reoperated due to bleeding compared with patients not using DOAC. In addition, more DOAC users were treated for late cardiac tamponade and the number of transfusions was higher (table 4).

\section{Survival analyses}

In the univariate analysis, DOAC use had the highest HR of 9.6 (3.1 to 29 ), $\mathrm{p}=0.00007$ (table 5).

Crude survival for DOAC users and warfarin users are presented in figure 1. For the final Cox proportional hazards model age was included, as patients using DOAC were older, and warfarin use was included for comparison, in addition to the four variables identified by LASSO regression (figure 2). DOAC use was also in the multivariate analysis highly significant with a hazard rate of 6.1 (1.4 to 26.4), $\mathrm{p}=0.015$. Warfarin use was not associated with increased operative mortality, neither in the univariate (HR 2.1 (0.49 to 9.1), $\mathrm{p}=0.32$ ) nor in the multivariate (HR 1.9 (0.4 to 9.0), $\mathrm{p}=0.42$ ) analyses. Adjusted survival curves for DOAC users and warfarin users are presented in figure 3. We also performed a multivariate analysis using the variables identified in the univariate analysis (table 5). In this model, extracardiac arteriopathy, chronic pulmonary disease and critical preoperative state 


\section{Survival}

Strata - Not using DOAC - Using DOAC

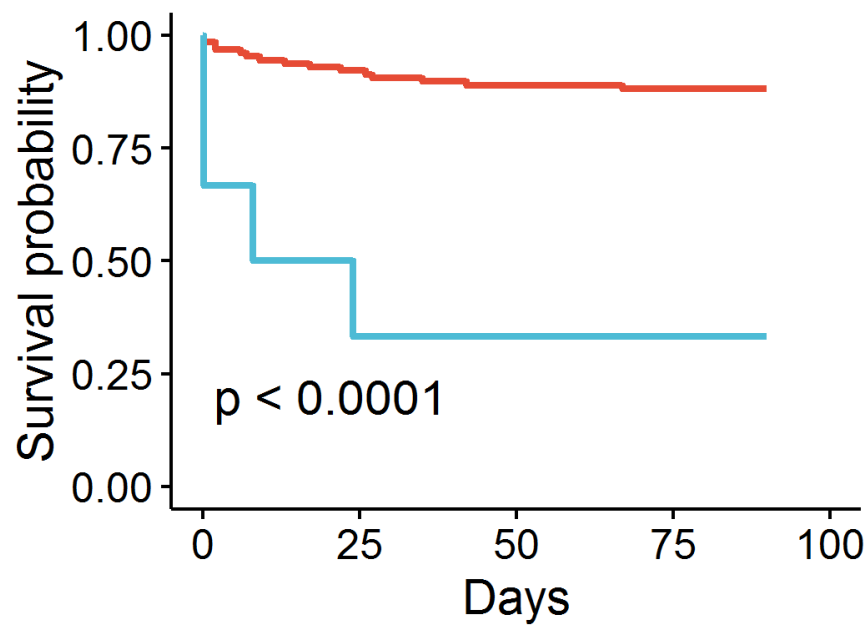

Strata - Not using warfarin - Using warfarin

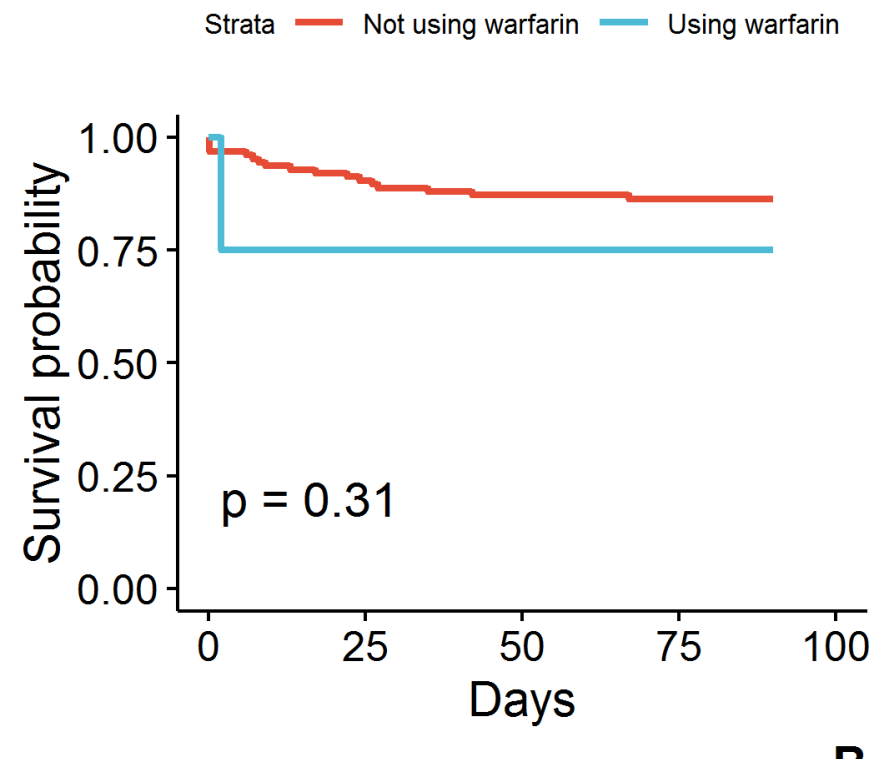

B

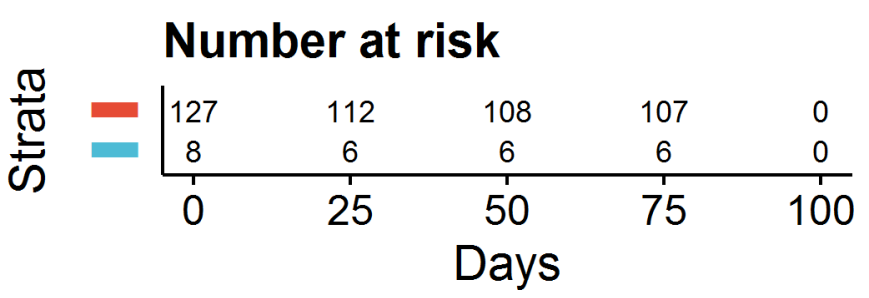

Figure 1 Unadjusted operative survival for patients using DOAC versus patients not using DOAC (A). Unadjusted operative survival for patients using warfarin versus patients not using warfarin (B). DOAC, direct oral anticoagulants.

did not meet the assumption of proportional hazards and were not included in this analysis. The analysis gave the same main finding and the results are presented in the supplement (online supplementary figure 1 ). We then reduced the number of covariates by stepwise selection and created a Cox model using these covariates as well as warfarin and age, and this analysis gave principally the same results as the model based on the LASSO regression. The results and are presented in the supplement (online supplementary figure 2).

\section{DISCUSSION}

Following the increased use of DOACs, we have gained experience in operating patients using these anticoagulants. In this study, including non-elective operations on the proximal aorta due to aortic disease, there was a striking and significant increase in operative mortality in DOAC users and all deaths among the DOAC treated patients were bleeding related. For dabigatran (factor IIa inhibitor), an antidote (idarucizumab) is now available, but for the factor Xa inhibitors (apixaban, rivaroxaban and edoxaban), the antidote (andexanet alfa) is not yet approved in Norway, and is not available to us. Hence, especially in the setting of acute cardiac surgery,
DOAC use has been cumbersome, as withdrawal is not an option. To analyse this clinical impression, we explored the department's quality register and identified nonelective surgery on the proximal aorta to be associated with obvious increased operative mortality. To study this effect, we performed univariate and multivariate analyses. We found the hazard rate associated with DOAC use to be significantly increased, while this was not found for warfarin.

The DOACs have gained popularity and are now the most used anticoagulants in Norway. Thus, the number of DOAC users requiring acute cardiac surgery is also likely to increase. As only $8 \%$ use dabigatran, we have yet to gain experience with the dabigatran antidote. Apixaban is the most used anticoagulant in Norway and even though plasma level analyses are available at our institution, there are no clear guidelines as to what levels would be considered therapeutic. Furthermore, as andexanet alfa may have effects on antithrombin mediated anticoagulation, ${ }^{8}$ the safety of andexanet alfa in open heart surgery requiring full-heparinisation remains to be demonstrated. In recent cases, we have used activated recombinant coagulation factors to reduce bleeding complications in DOAC users undergoing acute cardiac 


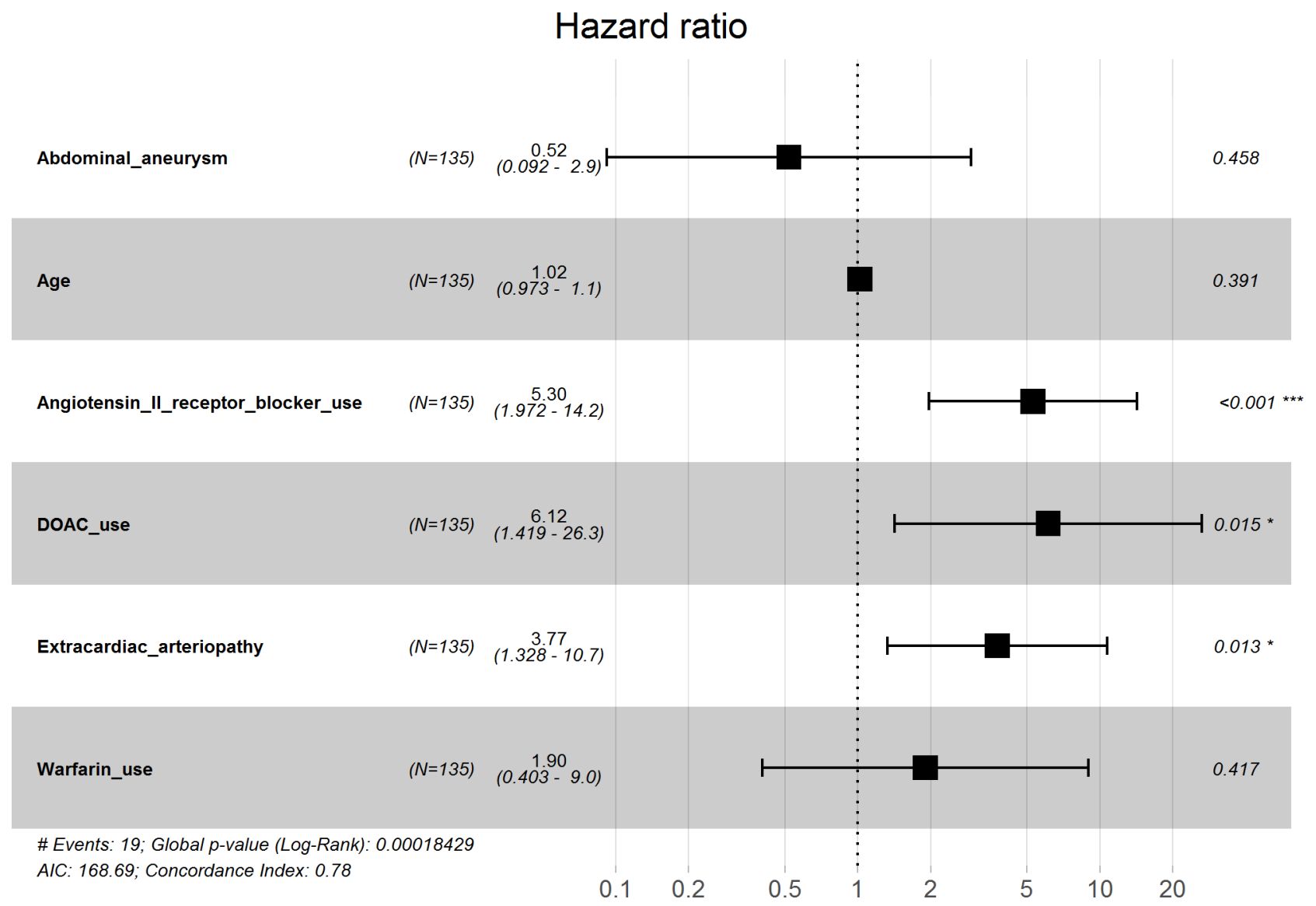

Figure 2 Forest plot from the final multivariate model. DOAC, direct oralanticoagulants. ${ }^{*} \mathrm{p}<0.05,{ }^{* \star *} \mathrm{p}<0.001$

surgery. We have also postponed surgery to allow for DOAC withdrawal in haemodynamically stable patients. DOACs are routinely withdrawn 5 days prior to elective surgery in our department. Even though our experience with this strategy is promising, the risk of inducing thromboembolic events or allowing for critical complications,

\section{Adjusted survival}

$$
\text { Strata - Not using DOAC — Using DOAC }
$$

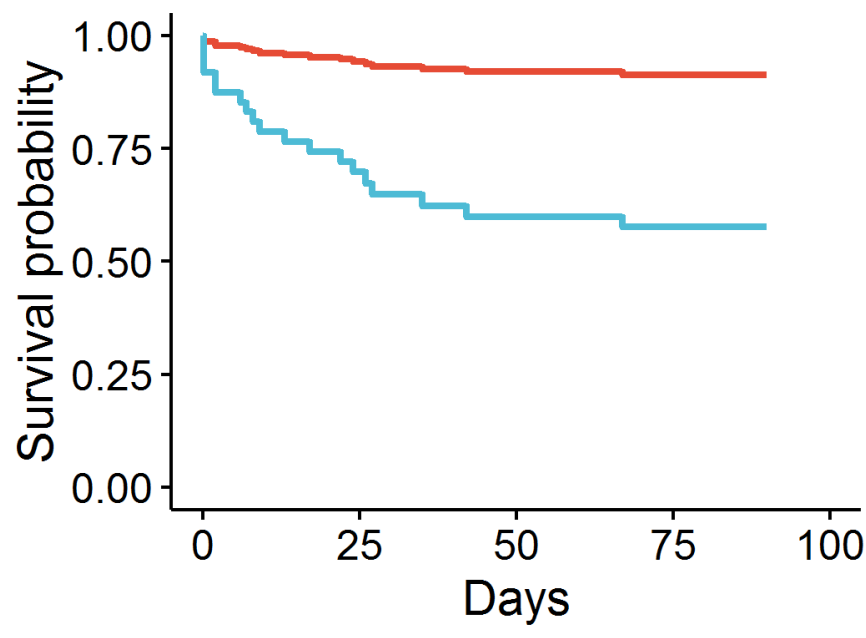

Strata - Not using warfarin $=$ Using warfarin

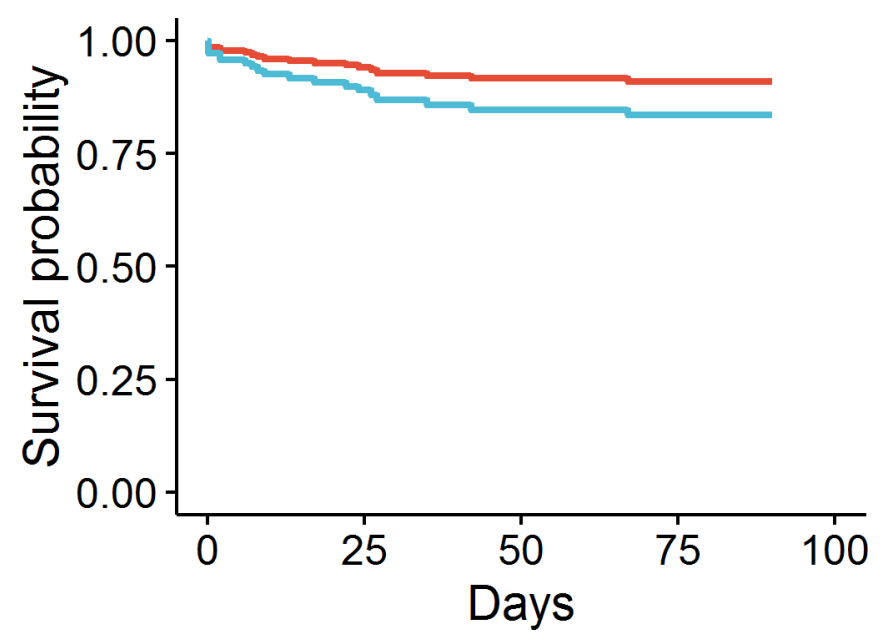

B

Figure 3 Adjusted operative survival for patients using DOAC versus patients not using DOAC (A). Adjusted operative survival for patients using warfarin versus patients not using warfarin (B). DOAC, direct oralanticoagulants. 
such as cardiac tamponade, to develop before surgery is of concern.

In this study, we did not find any increased risk associated with warfarin use. The anticoagulant effect of warfarin can and should be measured by INR and may be corrected using vitamin $\mathrm{K}$ or, in case of excess bleeding, by recombinant coagulation factors or plasma. This makes warfarin an easier drug to handle for the surgeons. In this study, three out of eight of the patients using warfarin were operated after already having undergone sternotomy; however, previous sternotomy was not a risk factor in our study as all four patients with previous sternotomy survived. Warfarin treatment needs to be monitored by INR and the dose adjusted accordingly. Hence, warfarin treatment is a skill and loss of experience in dosing warfarin may diminish the warfarin treatment skills. Traditionally, warfarin treatment in Norway has been safe due to the organising of primary care and reimbursements for INR controls. In recent years, the option of INR self-testing is more widely available due to new reimbursement rules. ${ }^{9}$ Home monitoring of INR has gained popularity, especially among younger patients.

In addition to DOACs, angiotensin II receptor blockers were in all analyses associated with increased operative risk. This medicine may be used because of hypertension, heart failure or both and $18 \%$ of the patients were registered as users of angiotensin II receptor blockers. Most patients in this material had hypertension registered as a risk factor, with $86 \%$ of warfarin users and $83 \%$ of DOAC users scored in the register. Angiotensin II receptor blockers are potent drugs, but we can, in this study, not suggest whether the increased risk is due to the drug itself or to the disease indicating the use of angiotensin II receptor blockers. However, the finding of increased risk associated with DOAC use was the only significant risk factor when performing multivariate analysis on the 20 factors identified in the univariate analysis (online supplementary figure 1 ).

In our material, proximal aortic surgery was the most frequent true emergency, as thoracic transplants are carefully screened and closely followed prior to transplant. Endocarditis or acute coronary syndromes are treated on an urgent basis, but the condition may allow a few days postponement to withdraw anticoagulants before surgery. Surgery for type A aortic dissections may be a special circumstance with respect to anticoagulants, as activation of the coagulation cascade inevitably occurs due to the disease. The operation requires full heparinisation and usually deep hypothermic circulatory arrest; hence, coagulopathy is a common clinical situation. However, the obvious difference in survival, revision for bleeding, and the trends for transfusions between warfarin and DOACs should warrant concern, especially in the case of type A aortic dissection. A German study of 81 consecutive patients undergoing open-heart surgery recently described effects of the DOAC withdrawal interval on postoperative bleeding, re-thoracotomy and intensive care unit stay, and recommended a need for up to 10 days withdrawal prior to cardiac surgery, in particular for patients with reduced renal function. ${ }^{7}$ In patients using rivaroxaban or ticagrelor, the same group has also described promising effects of CytoSorb $®$, a whole blood adsorber for extracorporeal purification of blood that may be used with a heart-lung machine during cardiac surgery. ${ }^{10}$ In another recent German study, warfarin use in patients surviving acute type A aortic dissection was not related to late mortality or aortic growth. ${ }^{11}$

Aortic dissection is not a very common disease, but it is a frequent surgical emergency in a cardiothoracic surgical department. In our region with 3 million inhabitants, 50 to 60 patients are operated for acute type A aortic dissection annually.

This study has several limitations. As an open label, non-randomised retrospective study of 135 cases, of which only six used DOAC, a firm conclusion cannot be drawn. On a yearly basis, our department treats a fair amount of aortic dissections. High volumes makes it possible to identify adverse effects observed as changes in practice for adjoining therapies occur, as for anticoagulant use in our study. Such observations require high volumes and may be difficult to identify within a reasonable time period. Thus, our caseload of aortic dissections is a strength. Hence, this study may highlight the possibility of catastrophic bleeding in patients using anticoagulants without an antidote available.

\section{CONCLUSION}

We report increased operative mortality in DOAC users undergoing non-elective operations on the proximal aorta due to aortic disease. In DOAC users, all deaths were due to bleeding-related complications. Hence, risk factors for aortic dissection, such as enlarged ascending aorta, family history, coarctation of the aorta, severe hypertension and aortic insufficiency, should be taken into consideration when prescribing anticoagulant medication. $^{12} 13$

Contributors JLB: Project idea, data acquisition, analysis and writing. He is the corresponding author and the one being responsible for the overall content. AMK: Data acquisition, writing/editing assistance. HR-U: Data acquisition, writing/editing assistance. BB: Project idea, writing/editing assistance. SN: Statistical supervisor. TNH: Project idea, data acquisition, writing/editing assistance. PSL: Project idea, data acquisition, writing/editing assistance.

Funding This work was supported by Oslo University Hospital.

Competing interests None declared.

Patient consent for publication Not required.

Ethics approval The study complies with the Declaration of Helsinki. The Regional Committees for Medical and Health Research Ethics have approved the research protocol and also waived the need for informed consent due to the nature of the study and according to Norwegian law regulating Health Research.

Provenance and peer review Not commissioned; externally peer reviewed.

Data availability statement Anonymised data may be shared upon reasonable request.

Open access This is an open access article distributed in accordance with the Creative Commons Attribution Non Commercial (CC BY-NC 4.0) license, which permits others to distribute, remix, adapt, build upon this work non-commercially, and license their derivative works on different terms, provided the original work is 
properly cited, appropriate credit is given, any changes made indicated, and the use is non-commercial. See: http://creativecommons.org/licenses/by-nc/4.0/.

\section{ORCID iDs}

Johannes Lagethon Bjørnstad http://orcid.org/0000-0001-9031-342X

Bjørn Bendz http://orcid.org/0000-0002-1392-6481

\section{REFERENCES}

1 Pagano D, Milojevic M, Meesters MI, et al. 2017 EACTS/EACTA guidelines on patient blood management for adult cardiac surgery. Eur J Cardiothorac Surg 2018;53:79-111.

2 Granger CB, Alexander JH, McMurray JJV, et al. Apixaban versus warfarin in patients with atrial fibrillation. $N$ Engl $\mathrm{J}$ Med 2011;365:981-92.

3 Connolly SJ, Ezekowitz MD, Yusuf S, et al. Dabigatran versus warfarin in patients with atrial fibrillation. $N$ Engl J Med 2009;361:1139-51.

4 Giugliano RP, Ruff CT, Braunwald E, et al. Edoxaban versus warfarin in patients with atrial fibrillation. N Engl J Med 2013;369:2093-104.

5 Patel MR, Mahaffey KW, Garg J, et al. Rivaroxaban versus warfarin in nonvalvular atrial fibrillation. N Engl J Med 2011;365:883-91.

6 Eek AK, Strøm BO, Bakkehøi G, et al. Anticoagulant-Associated adverse drug reactions in 2013-15. Tidsskr Nor Laegeforen 2018;138. [Epub ahead of print: 21 Aug 2018].
7 Hassan K, Bayer N, Schlingloff F, et al. Bleeding complications after use of novel oral anticoagulants in patients undergoing cardiac surgery. Ann Thorac Surg 2018;105:702-8.

8 Siddiqui F, Tafur A, Ramacciotti LS, et al. Reversal of factor Xa inhibitors by Andexanet alfa may increase thrombogenesis compared to pretreatment values. Clin Appl Thromb Hemost 2019; 25:1076029619863493:107602961986349.

9 Garcia-Alamino JM, Ward AM, Alonso-Coello P, et al. Self-Monitoring and self-management of oral anticoagulation. Cochrane Database Syst Rev 2010:CD003839.

10 Hassan K, Kannmacher J, Wohlmuth P, et al. Cytosorb adsorption during emergency cardiac operations in patients at high risk of bleeding. Ann Thorac Surg 2019;108:45-51.

11 von Kodolitsch $\mathrm{Y}$, Wilson $\mathrm{O}$, Schüler $\mathrm{H}$, et al. Warfarin anticoagulation in acute type $A$ aortic dissection survivors (WATAS). Cardiovasc Diagn Ther 2017;7:559-71.

12 Gawinecka J, Schönrath F, von Eckardstein A. Acute aortic dissection: pathogenesis, risk factors and diagnosis. Swiss Med Wkly 2017;147:w14489.

13 Erbel R, Aboyans V, Boileau C, et al. 2014 ESC guidelines on the diagnosis and treatment of aortic diseases: document covering acute and chronic aortic diseases of the thoracic and abdominal aorta of the adult. The task force for the diagnosis and treatment of aortic diseases of the European Society of cardiology (ESC). Eur Heart J 2014;35:2873-926. 